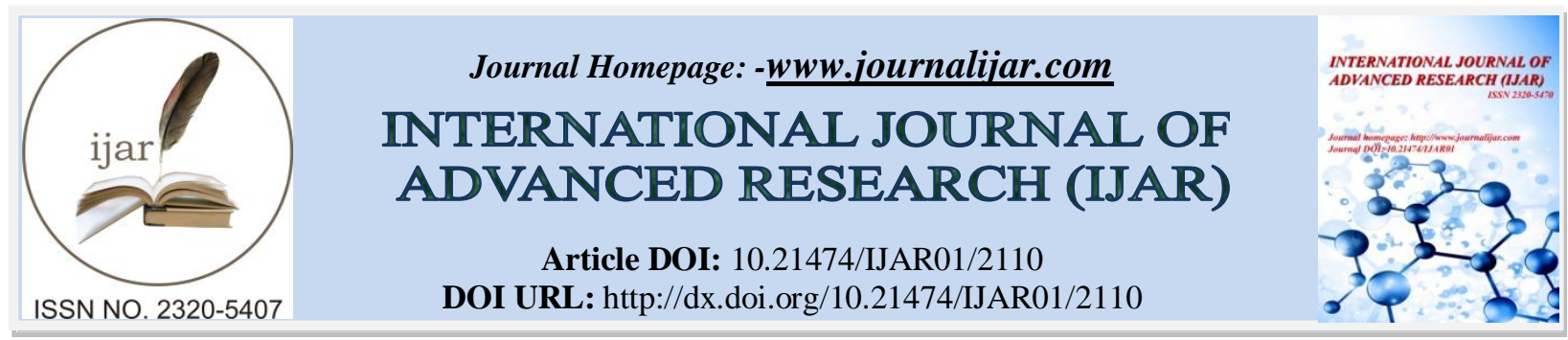

RESEARCH ARTICLE

\title{
COMPARISON OF $\mathrm{LaBr}_{3}(\mathrm{CE})$ AND NaI(TL) SCINTILLATION CRYSTALS RESPONSES TO VARIOUS GAMMA ENERGIES USING MONTE CARLO SIMULATIONS.
}

\section{R. Bagheri ${ }^{1}$, B. Heidari ${ }^{2}$, B. Ahmadi ${ }^{3}$, S. P. Shirmardi ${ }^{1}$ and S.Tuzemen ${ }^{4}$.}

1. Nuclear Fuel Cycle Research School, Nuclear Science and Technology Research Institute, Tehran, Iran.

2. Laser and Optic Research School, Nuclear Science and Technology Research Institute, Tehran, Iran.

3. Department of Physics, Faculty of Science, Urmia University, Urmia, Iran.

4. Department of Physics, Faculty of Science, Ataturk University, Erzurum, Turkey.

\section{Manuscript Info}

(.........................

Manuscript History

Received: 25 September 2016

Final Accepted: 27 October 2016

Published: November 2016

Key words:-

$\mathrm{LaBr}_{3}(\mathrm{Ce}), \mathrm{NaI}(\mathrm{Tl})$, Scintillation,

Crystal response, Monte Carlo

Simulations

\section{Abstract}

In this study, MCNP and FLUKA codes were applied for simulating and comparing of crystal response of $\operatorname{LaBr}_{3}(\mathrm{Ce})$ and $\mathrm{NaI}(\mathrm{Tl})$ scintillation detectors to gamma radiation of various radionuclides. Simulation results were compared with experimental data obtained from common real detectors containing these crystals. The results showed considerable differences between response of crystals and real detectors for low energy gamma rays which is mainly due to difference in simulated and experimental geometries. Also it is represented that $\mathrm{LaBr}_{3}(\mathrm{Ce})$ crystal is able to find energy peaks faster than $\mathrm{NaI}(\mathrm{Tl})$.

Copy Right, IJAR, 2016,. All rights reserved.

\section{Introduction:-}

Using scintillation light produced in certain materials for the detection of ionizing radiations, is one of the oldest methods on record. The scintillation process is one of the most beneficial techniques available for the detection and spectroscopy of wide types of radiations (Knoll, 2000). Scintillation spectrometers are widely utilized in detection and spectroscopy of the high energy photons ( $\gamma$-rays) ( Kleinknecht,1998; Regis et al., 2010). These detectors are commonly applied in nuclear and high-energy physics researches, medical imaging, diffraction, non-destructive testing, and geological exploration (Moses,et al.,2005; Kurosawa,et al., 2010). There are two types of scintillator detectors, organic, and inorganic. The scintillation process in inorganic materials depends on the energy bands determined by the crystal lattice of the material. One of the most applicable inorganic scintillator, is crystalline sodium iodide, in which a trace of thallium is added as an activator [NaI(Tl)] (Knoll, 2000).

In the past few years, a new cerium doped halide scintillator, $\mathrm{LaBr}_{3}(\mathrm{Ce})$ has been developed which has attractive properties such as temperature stability, very high light yield, low decay constant (Van,et al., 2001; Zhu,et al., 1982), excellent energy resolution, high count rate capability (Rosson,et al.,2011; Löher,et al., 2012), high gammaray detection efficiency, and optimistic technology for manufacturing crystal at larger sizes (Iltis,et al., 2006). This scintillation detector has recently become commercially available. Although growing the crystals has been proven somewhat difficult, but they are now available commercially in the sizes up to $3 \times 3$ inches from Saint-Gobain (SaintGobain Crystals and Detectors, Nemours, France) (Milbrath,et al., 2007). The characteristics of mentioned inorganic scintillators are listed in Table 1 for comparison (Knoll, 2000;Iltis,et al., 2006;Shah,et al., 2013).

Corresponding Author:- B. Heidari.

Address:-Laser and Optic Research School, Nuclear Science and Technology Research Institute, Tehran, Iran. 
Table 1:- Properties of two inorganic scintillators studied in this research.

\begin{tabular}{|l|l|l|l|l|l|}
\hline Scintillator & $\begin{array}{l}\text { Density } \\
\left(\mathrm{g} / \mathrm{cm}^{3}\right)\end{array}$ & $\begin{array}{l}\text { scintillation } \\
\text { light decay } \\
\text { constant }(\mathrm{ns})\end{array}$ & $\begin{array}{l}\text { Light yield } \\
(\text { Photons/MeV) }\end{array}$ & $\begin{array}{l}\text { FWHM in 0.662 } \\
\mathrm{MeV}(\%)\end{array}$ & $\begin{array}{l}\text { Wavelength of max. } \\
\text { emission }(\mathrm{nm})\end{array}$ \\
\hline $\mathrm{LaBr}_{3}(\mathrm{Ce})$ & 5.29 & 26 & 63000 & $\sim 3-4$ & 357 \\
\hline $\mathrm{NaI}(\mathrm{Tl})$ & 3.67 & 250 & 39000 & $6-7$ & 415 \\
\hline
\end{tabular}

The detector efficiency is easily determined via computational approach. Monte Carlo simulations have been widely applied for detector modelling and efficiency calculations (Garcia-Talavera,et al., 2000;Van, Ngoc,et al., 2007) Although, the accuracy of such simulation techniques must be validated before combining them to the laboratory routine, several studies have been published about the response of high-resolution gamma-ray spectrometers with Monte Carlo calculations. Most of them reported in agreement with experimental results (Garcia-Talavera,et al., 2000; Van,et al., 2007;Debertin,et al., 1982; Sánchez,et al., 1982; Decombaz,et al., 1992;Overwater,et al., 1993), except for the low-energy ranges. In the real case, it is not commonly possible to know the response of the detector crystal itself (without holder and exit window of the detector). Monte Carlo simulation has capability to calculate the crystal response to different gamma energies.

In this study, MCNP and FLUKA Monte Carlo codes were applied for modelling and comparing of the $\mathrm{LaBr}_{3}(\mathrm{Ce})$ and $\mathrm{NaI}(\mathrm{Tl})$ Scintillation crystals responses to gamma radiation originated from different radionuclides. The calculated results were compared with experimental data obtained from frequent real detectors for these crystals.

\section{Materials and Methodes:- Monte carlo simulations:-}

Monte Carlo simulations were performed using MCNP (version 4C) and FLUKA (version 2011.2-17) codes. They are general purpose tools for calculations of particles transport and interactions with materials (Briesmeister,et al., 2000; Ferrari,et al., 2005).

\section{Monte carlo codes:-}

The MCNP4C code:-

MCNP4C has capability to transport neutron, photon and electron or coupled neutron/photon/electron. This code utilized continuous-energy, nuclear and atomic data libraries. Photon interaction tables apply for all elements from $\mathrm{Z}$ $=1$ to $\mathrm{Z}=94$. The data in these tables allow MCNP to consider coherent and incoherent scattering, photoelectric absorption with the possibility of fluorescent emission in the photon transport. The detailed physics treatment is the default and contains form factors for electron binding effects, coherent (Thomson) scatter, and fluorescence from photoelectric capture (Briesmeister,et al., 2000; Shultis,et al., 2004).

\section{The FLUKA code:-}

FLUKA can simulate the interaction and propagation in matters of about 60 various particles with high accuracy. For the photon transport, photoelectric effect with real photoelectron angular distribution according to the fully relativistic theory of Sauter was taken into account. Interactions sampled separately for each component element and for each K edge as well. The edge fine structure is considered. Parameterizations/tabulations for photoelectric cross sections containing all known edges from a few eV up to $\mathrm{Z}=100$. Optional emission of fluorescence photons and approximate treatment of Auger electrons for all $\mathrm{K}$ and most L lines are existed. Compton effect with Doppler broadening are utilizing the appropriate form of the Compton profiles, and account for the atomic bonds by means of inelastic Hartree-Fock form factors. Rayleigh scattering was considered, and the Photon polarization was taken into account for Compton, Rayleigh, and photoelectric interactions. The lowest transport limit for the photons is $1 \mathrm{keV}$. Due to the lack of Coster-Kronig effect, fluorescence emission may be neglected at the energies lower than the Kedge in high- $\mathrm{Z}$ materials. The minimum recommended energy range for primary photons is about 5 to $10 \mathrm{keV}$. In this code, optical photons include Cherenkov, scintillation, and transition radiation can be generated and transported. It can also transport the light of given wavelength in the materials with user defined optical properties (Ferrari,et al., 2005).

\section{Simulation Procedure:-}

\section{Crystals geometries:-}

In both codes, cylindrical geometries were used for the crystals simulations corresponding to the crystals used in experimental measurements (Milbrath,et al., 2007). $\mathrm{LaBr}_{3}(\mathrm{Ce})$ crystal was simulated 1.5 inch in height and 1.5 inch 
in diameter and with $5.3 \mathrm{~g} / \mathrm{cm}^{3}$ density, while $\mathrm{NaI}(\mathrm{Tl})$ crystal, 2.2 inches in height and 1.5 inch in diameter, and 3.67 $\mathrm{g} / \mathrm{cm}^{3}$ density. The crystals were aligned with $\mathrm{y}$-axis and set from $\mathrm{y}=0$ to $\mathrm{y}=-1.5$ and $\mathrm{y}=0$ to $\mathrm{y}=-2.2$ inch, respectively. Figure 1 shows $\mathrm{NaI}(\mathrm{Tl})$ crystal dimensions and source position relative to it.

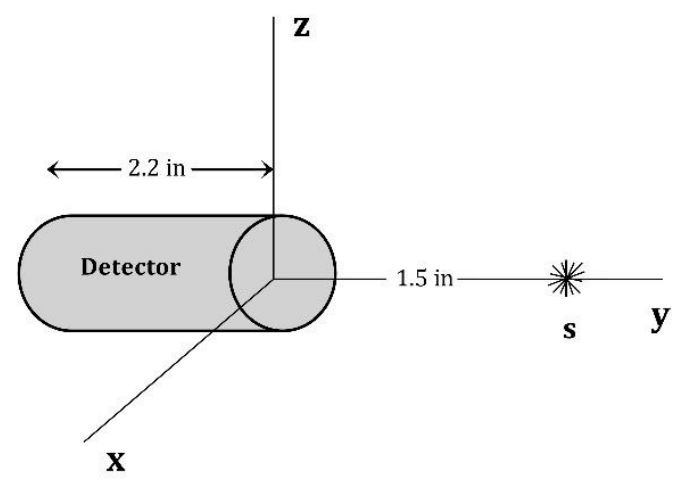

Fig 1:- $\mathrm{NaI}(\mathrm{Tl})$ detector dimensions and source position relative to it.

\section{Source Specification:-}

Definition of the sources in MCNP:-

Button sources such as experimental condition (Milbrath,et al., 2007)were specified as planar sources with uniform distribution of radioactive material upon them that emit gamma rays isotropically. These sources were assumed as a disc with $5 \mathrm{~cm}$ in diameter and parallel to $\mathrm{x}-\mathrm{y}$ plane in $(0,0,100)$ or $(0,0,10)$ origin coordinates. Sources energies, depending on radioactive materials, spam from $59.54 \mathrm{keV}$ for ${ }^{241} \mathrm{Am}$ in $10 \mathrm{~cm}$ distance from crystals to $1332.52 \mathrm{keV}$ for ${ }^{60} \mathrm{Co}$ radioisotope in $100 \mathrm{~cm}$. The activities of various sources were chosen different. Except for ${ }^{241} \mathrm{Am}(9.8 \mu \mathrm{Ci})$ and ${ }^{109} \mathrm{Cd}(6.7 \mu \mathrm{Ci})$ sources (because of their low gamma rays energies), the distant between the sources and the crystals was selected $100 \mathrm{~cm}$.

\section{Definition of the sources in FLUKA:-}

Because of source definition complexity (especially distributed radioactive sources on a plane or in a volume) in FLUKA, for the purpose of convenience, a beam with characteristics mentioned in Table 2 was simulated. The features of this beam are equal to the button sources used in experimental measurements and MCNP simulations. The position that the beam starts is the same as MCNP and measurement setups.

Table 2:- The characteristics of the beam equal to button sources simulated by the FLUKA code.

\begin{tabular}{|l|l|}
\hline Momentom spread type & Flat \\
\hline Momentum spread $(\mathrm{Gev} / \mathrm{c})$ & 0 \\
\hline Beam shape in $\mathrm{x}$ axis & Rectangular \\
\hline Beam shape in y axis & Rectangular \\
\hline Beam width in x direction $(\mathrm{cm})$ & 2.5 \\
\hline Beam width in y direction $(\mathrm{cm})$ & 2.5 \\
\hline Divergence type & Isotropic \\
\hline
\end{tabular}

For investigating of the simulated data accuracy, the button sources accompanied by shielding were studied. The shielding was 0.5 inch steel plate which was placed between the sources and the crystals at a distance of $20 \mathrm{~cm}$ from the crystals (Fig 2). 


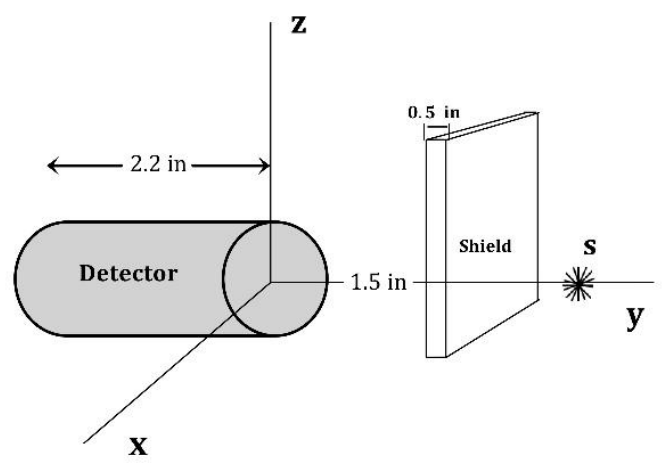

Fig 2:- The position of steel plate shield relative to simulated $\mathrm{NaI}(\mathrm{Tl})$ detector and button source.

\section{Crystals materials specification and amount of added activators:-}

$\mathrm{LaBr}_{3}(\mathrm{Ce})$ crystal was considered about $99.5 \%$ as combination of $\mathrm{LaBr}_{3}$ (one lanthanum ion $\mathrm{La}^{+3}$ with three bromine ion $\mathrm{Br}-1$ ) and $0.5 \%$ (concentration of cerium $\mathrm{Ce}^{+3}$ ) as a combination of $\mathrm{CeBr}_{3}$ (Dorenbos,et al., 2004) . Also for $\mathrm{NaI}(\mathrm{Tl})$ crystal, concentration of thallium activator similar to the most sodium iodide commercial crystals was regarded about $0.11 \%$ as a TII combination against $99.89 \% \mathrm{Na}$ as a $\mathrm{NaI}$ form (Saha, 2006).

\section{Tally definition:-}

F8 and DETECT pulse height tallies were utilized in MCNP4C and FLUKA simulations, respectively. In MCNP4C, F8 (pulse height tally), scores the energy distribution of pulses in a cell that simulate a physical detector. Its energy bins corresponds to the total energy deposited in a detector in the defined channels by each physical particle. This tally will not work with any variance reduction other than source biasing. Another aspect of the pulse height tally that is different from other MCNP tallies is that photon, electron and photon/electron modes of transport are all equivalent. All the energy from both photons and electrons, if present, will be deposited in the cell, no matter which tally is specified. Score value is zero if no track entered the cell during the history. Zero scores are due to particles passing through the pulse height cell without depositing energy. Therefore, it is possible to calculate the recorded number of counts in any channels corresponding to various energies per gamma photon that enter the detector.

In FLUKA, DETECT tally, scores energy deposition on an event by event basis (detector), providing coincidence and anti-coincidence capabilities such as those of a trigger. An "event" means energy deposited in the detector regions by one primary particle and its descendants. A "signal" means energy deposited in the detector by the same primary particle, and descendants. The output of DETECT is a distribution of energy deposited per event in detector. In this study, coincidence capability was selected as a trigger. For physics setting, the DEFAULTS card was set to EM-CASCAde in which electromagnetic interactions are considered. Generally, in this work, for both MCNP and FLUKA, $10^{6}-10^{8}$ photons histories were tracked for reaching the error of calculations below $5 \%$. The Monte Carlo simulations did not contain the light collecting and amplifying in the photo-cathode of the detector. Internal and external background counts did not considered in the simulations. The crystals of both detectors were just modelled in this study.

\section{Results and Discussions:-}

Non-shielded button sources calculations:-

Since Monte Carlo simulation results are calculated per particle, net area/net count of photopeaks for sources with various energies and for one gamma ray entrance in the crystals, were obtained from the calculations. For calculating of the total count caused by all the photons are emitted from the sources, as an example, the calculations for ${ }^{241} \mathrm{Am}$ are shown below. With assumption of the ${ }^{241} \mathrm{Am}$ button source has $9.8 \mu \mathrm{Ci}$ activity, for 10 second counting (by means of $\mathrm{LaBr}_{3}(\mathrm{Ce})$ crystal), occurs about:

$9.8 \mu \mathrm{Ci} \times 3.7 \times 10^{4}$ dis. $\mathrm{s}^{-1} / \mu \mathrm{Ci} \times 10 \mathrm{~s}=3.626 \times 10^{6}$ disintegrations.

Considering about $35.9 \%$ of ${ }^{241} \mathrm{Am}$ atoms disintegrations produce gamma ray with $59.54 \mathrm{keV}$ energy, the total number of the photons emitted with this energy (in $10 \mathrm{sec}$ counting) would be equal to:

$3.626 \times 106 \times(35.9 / 100)=1.302 \times 10^{6}$ photons.

As such, the net count of the crystal using MCNP simulated results is as follow:

$7.63 \times 10^{-3}$ counts/photon $\times 1.302 \times 10^{6}$ photon $=9934$ counts. 
For all the sources, similar calculations were performed. The results were shown in Tables 3 , and 4.

Table 3:-Comparison between the simulated and experimental data obtained from 10 second counting of button sources (without background) using $\mathrm{LaBr}_{3}(\mathrm{Ce})$ and $\mathrm{NaI}(\mathrm{Tl})$ detectors.

\begin{tabular}{|c|c|c|c|c|c|c|c|c|c|}
\hline \multirow[t]{3}{*}{ Isotope } & \multirow{3}{*}{$\begin{array}{l}\text { Energy } \\
(\mathrm{keV})\end{array}$} & \multirow{3}{*}{$\begin{array}{l}\text { Activity } \\
(\mu \mathrm{Ci})\end{array}$} & \multirow{3}{*}{$\begin{array}{l}\text { Distance } \\
\text { from } \\
\text { detector } \\
(\mathrm{cm})\end{array}$} & \multicolumn{6}{|c|}{ Net area of photopeak } \\
\hline & & & & \multicolumn{3}{|c|}{$\mathrm{LaBr}_{3}: \mathrm{Ce}$} & \multicolumn{3}{|c|}{$\mathrm{NaI}(\mathrm{Tl})$} \\
\hline & & & & MCNP & FLUKA & Exp. ${ }^{*}$ & MCNP & FLUKA & Exp. \\
\hline${ }^{241} \mathrm{Am}$ & 59.54 & 9.8 & 10 & 9934 & 10447 & 9644 & 9580 & 9864 & 6261 \\
\hline${ }^{133} \mathrm{Ba}$ & 81.01 & 28.8 & 100 & 318 & 311 & 213 & 309 & 297 & 124 \\
\hline${ }^{109} \mathrm{Cd}$ & 88.04 & 6.7 & 10 & 726 & 735 & 473 & 704 & 705 & 374 \\
\hline${ }^{57} \mathrm{Co}$ & 122.07 & 37.1 & 100 & 1046 & 994 & 749 & 1033 & 976 & 526 \\
\hline${ }^{133} \mathrm{Ba}$ & 276.29 & 28.8 & 100 & 62 & 52 & 30 & --- & --- & --- \\
\hline${ }^{133} \mathrm{Ba}$ & 302.71 & 28.8 & 100 & 142 & 126 & 43 & --- & --- & --- \\
\hline${ }^{133} \mathrm{Ba}$ & 355.86 & 28.8 & 100 & 351 & 373 & 330 & 347 & 383 & 318 \\
\hline${ }^{133} \mathrm{Ba}$ & 383.70 & 28.8 & 100 & 50 & 48 & 16 & --- & --- & --- \\
\hline${ }^{137} \mathrm{Cs}$ & 661.62 & 9.1 & 100 & 108 & 110 & 78 & 92 & 93 & 96 \\
\hline${ }^{60} \mathrm{Co}$ & 1172.23 & 7.1 & 100 & 48 & 45 & 36 & 43 & 39 & 19 \\
\hline${ }^{60} \mathrm{Co}$ & 1332.51 & 7.1 & 100 & 43 & 36 & 19 & 39 & 33 & 16 \\
\hline
\end{tabular}

Milbrath, et al., 2007.

Table 4:- Comparison of experimental and simulated data for 180 and 200 second counting of shielded button sources using $\mathrm{LaBr}_{3}(\mathrm{Ce})$ and $\mathrm{NaI}(\mathrm{Tl})$ detectors respectively.

\begin{tabular}{|c|c|c|c|c|c|c|c|c|c|}
\hline \multirow[t]{3}{*}{ Isotope } & \multirow{3}{*}{$\begin{array}{l}\text { Energy } \\
(\mathrm{keV})\end{array}$} & \multirow{3}{*}{$\begin{array}{l}\text { Activity } \\
(\mu \mathrm{Ci})\end{array}$} & \multirow{3}{*}{$\begin{array}{l}\text { Distance } \\
\text { from } \\
\text { detector } \\
(\mathrm{cm})\end{array}$} & \multicolumn{6}{|c|}{ Net area of photopeak } \\
\hline & & & & \multicolumn{3}{|c|}{$\mathrm{LaBr}_{3}: \mathrm{Ce}$} & \multicolumn{3}{|l|}{$\mathrm{NaI}(\mathrm{Tl})$} \\
\hline & & & & MCNP & FLUKA & Exp. & MCNP & FLUKA & Exp." \\
\hline${ }^{57} \mathrm{Co}$ & 122.07 & 37.1 & 100 & 1808 & 1647 & 1499 & 2012 & 1959 & 1622 \\
\hline${ }^{133} \mathrm{Ba}$ & 302.71 & 28.8 & 100 & 927 & 844 & 620 & 1015 & 910 & 631 \\
\hline${ }^{133} \mathrm{Ba}$ & 355.86 & 28.8 & 100 & 2399 & 2583 & 2245 & 2591 & 3081 & 2393 \\
\hline${ }^{137} \mathrm{Cs}$ & 661.62 & 9.1 & 100 & 867 & 854 & 622 & 918 & 840 & 601 \\
\hline${ }^{60} \mathrm{Co}$ & 1172.23 & 7.1 & 100 & 485 & 461 & 495 & 499 & 460 & 372 \\
\hline${ }^{60} \mathrm{Co}$ & 1332.51 & 7.1 & 100 & 451 & 416 & 397 & 444 & 415 & 317 \\
\hline
\end{tabular}

Milbrath, et al., 2007.

In Table 3, simulated and experimental data obtained from 10 second button source counting (without background) using $\operatorname{LaBr}_{3}(\mathrm{Ce})$ and $\mathrm{NaI}(\mathrm{Tl})$ crystals were compared.

Simulated results calculated by means of MCNP4C and FLUKA codes represent that for $\operatorname{LaBr}_{3}(\mathrm{Ce})$ crystal, net area of photopeak for each source (corresponding to various energies) is greater than $\mathrm{NaI}(\mathrm{Tl})$. In other words, the simulated data states that $\mathrm{LaBr}_{3}(\mathrm{Ce})$ crystal can measure peaks with different energies faster than the $\mathrm{NaI}(\mathrm{Tl})$ crystal. Also, it can be said that for counting the same number of photons (with certain energy), NaI(Tl) crystal needs more counting time than $\mathrm{LaBr}_{3}(\mathrm{Ce})$ crystal. For $\mathrm{LaBr}_{3}(\mathrm{Ce})$, maximum difference between codes prediction is $19.44 \%$. For both crystals, simulated results are close to the experimental data in $355.86 \mathrm{keV}$ (maximum difference $9.11 \%$ and $20.44 \%$ for MCNP and FLUKA, respectively). For NaI(Tl), there is a good agreement between the simulation and experiment in ${ }^{137} \mathrm{Cs}$ energy (96.87\% agreement). As such, in short counting time (non-shielded condition), there is not good accommodation between simulated results and experimental data in most cases due to difference in simulated geometries and the real detectors (containing holder and exit window of the detectors).

\section{Shielded button sources calculations:-}

For better comparison of the two crystals, in Table 4, the simulated data of shielded button sources was compared with the experimental measurements obtained from Ref. (Milbrath,et al., 2007).In Table 4, experimental and simulated data indicate that although $\mathrm{NaI}(\mathrm{Tl})$ crystal had counted more time (200 second) than $\mathrm{LaBr}_{3}(\mathrm{Ce})$ crystal (180 second), but due to the high intrinsic efficiency of $\mathrm{LaBr}_{3}(\mathrm{Ce})$ in relative to $\mathrm{NaI}(\mathrm{Tl})$ (Iltis,et al., 2006), the recorded number of the photons for each of the sources using both crystals are almost equal. This also state that 
$\mathrm{LaBr}_{3}(\mathrm{Ce})$ crystal is able to find energy peaks faster than $\mathrm{NaI}(\mathrm{Tl})$. For $\mathrm{LaBr}_{3}(\mathrm{Ce})$, unlike $\mathrm{NaI}(\mathrm{Tl})$, the simulation are close to experiment in most cases. For both crystals, maximum difference between the codes was $15.9 \%$. For $\mathrm{LaBr}_{3}(\mathrm{Ce})$ and $\mathrm{NaI}(\mathrm{Tl})$, maximum differences between the simulated results and experimental data were $49.52 \%$, $37.3 \%, 60.86 \%$ and $44.22 \%$ for MCNP4C and FLUKA, respectively. The best agreement between the simulated and experimental data was for ${ }^{60} \mathrm{Co}$ counting by $\mathrm{LaBr}_{3}(\mathrm{Ce})$ (more than $86.4 \%$ ). Some factors which limited the accuracy of the Monte Carlo simulated efficiency are the following (Garcia-Talavera,et al., 2000):

The uncertainties in the interaction parameters, such as cross sections and ranges, the simplifying supposition applied to simulate the interaction processes and the errors in the detector and source definition due to the lack of a precise knowledge of their characteristics.

In this study, the difference between the simulated results and experimental data may cause as follows; Monte Carlo method error, difference between simulated geometry and the real case which applied by Ref. (Milbrath,et al., 2007), not considering of the entrance window of the detectors, not considering of the crystal holder of the detectors, not considering the self-absorption of the sources.

\section{Conclution:-}

In this research, MCNP and FLUKA codes were applied for simulating and comparing of the $\mathrm{LaBr}_{3}(\mathrm{Ce})$ and $\mathrm{NaI}(\mathrm{Tl})$ scintillation crystals response to gamma radiation originated from different radionuclides. The simulated results were compared with the experimental data from the literature. There was a considerable difference between simulated results and experimental data in most energy (especially in low energies) related to the radionuclides. As such, in all cases, there is not good accommodation between simulated results and experimental data in most cases due to difference in simulated geometries and the real detectors (containing holder and exit window of the detectors). From the results of this study, It can be concluded that $\mathrm{LaBr}_{3}(\mathrm{Ce})$ crystal is capable of finding energy peaks faster than $\mathrm{NaI}(\mathrm{Tl})$. As such, it would be a good selection for the portable radioisotope identification devices.

\section{References:-}

1. Knoll, G. F. 2000. Radiation Detection and Measurements, 3rd ed. Wiley: New York, NY, USA.

2. Kleinknecht, K. 1998. Detectors for Particle Radiation, 2nd ed. Cambridge, U.K.

3. Smith, D. L.; Mach, H.; Penttila, H.; Bradley, H.; Aysto, J.; Elomaa, V. V.; Eronen, T.; Ghita D. G.; Hakala, J.; Hauth, M.et al. 2008.Phys. Rev. C. 77, 014309: 1-7.

4. Regis, J. M.; Pascovici, G.; Jolie, J.; Rudigier, M.2010.Nucl. Instr. Meth. A.622: 83-92.

5. Moses, W. W.; Shah, K. S.2005.Nucl. Instr. Meth. A. 537: 317-320.

6. Kulisek, J.; Hartwell, J.; McIlwain, M.; Gardner, R.2007.Nucl. Instr. Meth. A.580: 226-229.

7. Milbrath, B. D.; Choate, B. J.; Fast, J. E.; Hensley, W. K.; Kouzes, R. T.; Schweppe, J. E.2007.Nucl. Instr.

8. Meth. A. 572:774-784.

9. Kurosawa, S.; Kubo, H.; Hattori, K.; Ida, C.; Iwaki, S.; Kabuki, S.; Kubo, A.; Kunieda, E.; Miuchi, K.; Nakahara, T. et al.2010.Nucl. Instr. Meth. A. 623: 249-251.

10. Van, Loef, E. V. D.;Dorenbos, P.;Van, Eijk, C. W. E.;Krämer, K.;Güdel, H. U. 2001. Appl. Phys. Lett.79:1573-

11. 1575 .

12. Van, Loef, E. V. D.; Dorenbos, P.; Van, Eijk, C. W. E.; Krämer, K. W.; Güdel, H. 2002. Nucl. Instr. Meth. A.

13. 486: 254-258.

14. Balcerzyk, M.; Moszynski, M.; Kapusta, M. 2005.Nucl. Instr. Meth. A. 537, 50-56.

15. Moszynski, M.; Gierlik, M.; Kapusta, M.; Nassalski, A.; Szczesniak, T.; Fontaine, C.; Lavoute, P.2006.Nucl. Instr. Meth. A. 567: 31-35.

16. Moszynski, M.; Nassalski, A.; Syntfeld-Kazuch, A.; Szczesniak, T.; Czarnacki, W.; Wolski, D.; Pausch, G.;

17. Stein, J.2006. Nucl. Instr. Meth. A.568: 739-751.

18. Iltis, A.; Mayhugh, M. R.; Menge, P.; Rosza, C. M.; Selles, O.,; Solovyev, V. 2006.Nucl. Instr. Meth. A. 563, 359-363.

19. Kramer, K. W.; Dorenbos, P.; Gudel, H. U.; Van, Eijk, C. W. E.2006.J. Mater. Chem. 16: 2773-2780.

20. Zhu, S.; Kondev, F.; Carpenter, M.; Ahmad, I.; Chiara, C.; Greene, J.; Gurdal, G.; Janssens, R.; Debertin, K.;

21. Grosswendt, B.1982.Nucl. Instr. Meth. A. 203: 343-352.

22. Rosson, R.;Lahr, J.;Kahn, B. 2011. Health Phys.101: 703-708.

23. Löher,B.; Savran,D.; Fiori,E.; Miklavec,M.; Pietralla,N.; Vencelj,M.2012.Nucl. Instr. Meth. A. 686: 1-6. 
24. Shah, K. S.;Glodo, J.;Klugerman, M.;Moses, W. W.;Derenzo, S. E.;Weber, M. J.2003.IEEE Trans. Nucl. Sci.,50, 2410-2413.

25. Garcia-Talavera, M.; Neder, H.; Daza, M. J.; Quintana, B. 2000.Appl. Radiat. Isot. 52 : 777-783 21.

26. Van, Ngoc, L.; Huyen, N. T. T.; Hao, Quang, N.2007.VNU.J. Sci.23: 99-104.

27. Debertin, K.; Grosswendt, B.1982. Nucl. Instr. Meth. A.203: 343-352.

28. Sánchez, F.; Navarro, E.; Ferrero, J. L.; Moreno, A.; Roldán, C.; Baeza, A.; Paniagua, A.1991.Nucl. Instr.

29. Meth.B. 61: 535-540.

30. Decombaz, M.; Gostely, J. J.; Laedermann, J. P.1992.Nucl. Instr. Meth. A.312: 152-159.

31. Overwater, M. W.; Bode, P.; de, Goeij, J.1993.Nucl. Instr. Meth. A.324, 209-218.

32. Briesmeister, J. F. MCNP; 2000. A General Monte Carlo N-particle Transport Code. Report LA-13709-M,

33. Version 4C, Los Alamos, USA.

34. Ferrari, A.; Sala, P. R.; Fasso, A.; Ranft. J.2005.FLUKA: A Multi-particle Transport CodeINFN/TC-05/11,

35. SLAC-R-773; CERN: Geneva, Switzerland.

36. Shultis, J. K.; Faw, R. E.2004 .An MCNP primer.Department of mechanical and nuclear engineering, Kansas state university.

37. Dorenbos, P.; De, Haas, J. T. M.; Van, Eijk, C. W. 2004.E.IEEE Trans. Nucl. Sci.51: 1289-1296.

38. Saha, G. B. 2006. Physics and Radiobiology of Nuclear Medicine. Springer; New York, NY, USA.91-107. 